\title{
Comparação de Modelos Neurais Aplicados a Resistência de Fornos de Redução do Alumínio Primário
}

\author{
Thiago N. M. S. Conte ${ }^{1}$ \\ Programa de Pós-Graduação em Engenharia Elétrica, Universidade Federal do Pará \\ Roberto Célio Limão de Oliveira ${ }^{2}$ \\ Programa de Pós-Graduação em Engenharia Elétrica, Universidade Federal do Pará
}

\begin{abstract}
Resumo. Este trabalho avalia alguns tipos de Redes Neurais Artificiais na tarefa de modelar dinamicamente o comportamento da resistência elétrica de um forno de redução de alumínio primário. A proposta é utilizar Redes Neurais Multicamada Diretas (RNMD) e Redes Neurais Recorrentes (RNR) para modelar a resistência elétrica do forno. Para cada uma destas Redes Neurais é explorada a sua capacidade de modelar sistemas dinâmicos, seja variando o número de camadas de neurônios, bem como o número de neurônios em cada camada, variando também os sinais de entrada da rede neural, etc. Os dados a serem utilizados na modelagem são oriundos de uma fábrica brasileira de alumínio primário. Esta modelagem pode ser usada para controlar a distância (subir ou descer) entre os anodos e catodos do forno de redução, procurando sempre garantir a produção do alumínio primário, com alto teor de pureza, com base em dados disponíveis online no sistema de controle da fábrica.
\end{abstract}

Palavras-chave. Redução de Alumínio, Modelagem Dinâmica, Inteligência Computacional, Redes Neurais Artificiais, Redes Neurais Recorrentes.

\section{Introdução}

Nas últimas décadas, com a crescente complexidade dos problemas a serem tratados computacionalmente e do volume de dados gerados em diferentes setores da indústria, tornou-se clara a necessidade de ferramentas computacionais mais sofisticadas, que fossem mais autônomas, reduzindo a necessidade de intervenção humana e dependência de especialistas. Para isso, essas técnicas deveriam ser capazes de criar por si próprio, a partir de experiência passada, uma hipótese, ou função, capaz de resolver o problema que se deseja tratar [3].

As Redes Neurais Artificiais representam uma tecnologia, da inteligência computacional, que tem raízes em muitas disciplinas: neurociência, matemática, física, ciência da computação e engenharia. As redes neurais encontram aplicações em campos tão diversos, como modelagem, análise de séries temporais, reconhecimentos de padrões, processamento de sinais e controle, em virtude de uma

${ }^{1}$ thiagonconte@gmail.com

${ }^{2}$ limao@ufpa.br 
importante propriedade: a habilidade de aprender a partir de dados de entrada com ou sem um professor, ou melhor, supervisão [4].

A modelagem da resistência elétrica no forno de redução do alumínio utilizandose de redes neurais artificiais é o principal assunto deste trabalho. $\mathrm{O}$ trabalho realizado por Marcos Vinícius [2] apresenta o uso de redes neurais do tipo MLP Diretas para modelagem da resistência do forno de redução de alumínio, porém, sem comparar os resultados obtidos com outros métodos ou arquiteturas de redes, além de não apresentar os valores de erros obtidos pelo modelo utilizado.

Dessa forma, o presente trabalho apresenta um comparativo entre os resultados gerados pelas Redes Neurais Multicamada Diretas e Redes Neurais Multicamadas Recorrentes.São utilizados dados do mundo real de um processo de fabricação de alumínio primário no Brasil. Assim, o objetivo desse trabalho é comparar as RNMD e RNMR na tarefa de modelagem do comportamento do forno de redução do alumínio primário.

\section{Processo de Fabricação de Alumínio Primário}

O alumínio não é encontrado em estado metálico na crosta terrestre. Sua obtenção parte da mineração da bauxita que é a principal matéria prima da alumina e segue para as etapas posteriores de refinamento e redução.

\subsection{Redução do Alumínio}

A obtenção do alumínio ocorre pela redução da alumina em fornos eletrolíticos, a altas temperaturas, no processo conhecido como Hall-Héroult, ou seja, dissociação das moléculas de alumina (Al2O3) em um banho químico para obtenção do alumínio líquido que se precipita no fundo do forno eletrolítico. A Figura 1 mostra o corte transversal do forno com seus elementos de interesse direto.

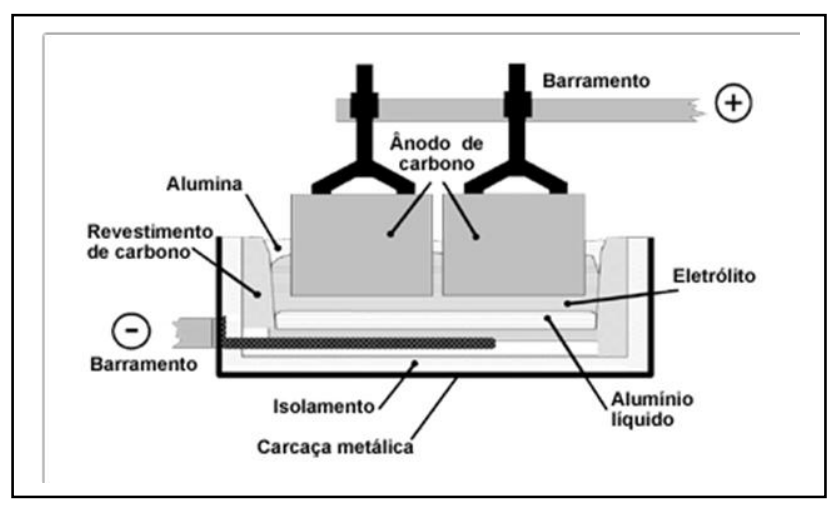

Figura 1: Forno Eletrolítico

\subsection{Controle de Resistência}

É fundamental que a resistência de um forno eletrolítico se mantenha estável, pois a oscilação da mesma acaba por ocasionar o superaquecimento do forno, 
impactando assim na perda da aresta, alto consumo de energia elétrica e emissão de gases para atmosfera. Além disso, gera a redução da amperagem da linha, e, consequentemente, afeta a voltagem dos fornos, uma vez que estas estão ligadas em série, e tensão efetiva (voltagem gerada pala própria reação química e resulta na produção do alumínio correspondendo a $1,65 \mathrm{~V}$ por forno) impactando assim na solubilidade da alumina e causando uma queda na produtividade $[7,6,8]$.

Para superar este obstáculo, pensou-se na utilização de uma técnica de inteligência computacional, especificadamente no uso de uma rede neural artificial (RNA) para modelar esta oscilação d resistência elétrica do forno, a partir de registros reais dos fornos.

O controle da resistência faz aquisição basicamente de dois sinais: intensidade da corrente e tensão do forno, como mostra na Equação 1.

$$
R_{\text {inst }}=\frac{V_{\text {inst }}-B_{\text {emf }}}{I}
$$

Tabela 1.Variáveis no controle de resistência do Forno

\begin{tabular}{|c|l|}
\hline Variável & \multicolumn{1}{|c|}{ Descrição } \\
\hline$R_{\text {inst }}$ & Resistência do forno (Micro Ohm $-\mu \Omega$ ) \\
\hline$V_{\text {inst }}$ & Tensão media para cada forno (Volt - V) \\
\hline$B_{\text {emf }}$ & Queda da tensão química (Volt - V) \\
\hline$I$ & Corrente (Quilo Ampere - KA) \\
\hline
\end{tabular}

\section{Redes Neurais Artificiais (RNAs)}

São sistemas de computação adaptativos, inspirados nas características de processamento de informação encontrados nos neurônios biológicos e nas características de suas interconexões. Desta forma, uma Rede Neural Artificial é constituída de dois tipos de elementos (Neurônios e Sinapses) e dois aspectos (arquitetura e aprendizado).

Os Neurônios Artificiais são unidades de processamento simples, conforme a Figura2, que computam funções matemáticas. Enquanto a arquitetura está relacionada ao tipo e o número de unidades de processamento e à forma como os neurônios estão conectados.

$\mathrm{Na}$ maioria das arquiteturas, essas conexões, que simulam as sinapses biológicas, possuem pesos associados que ponderam a entrada recebida por cada neurônio da rede. Os pesos podem assumir valores positivos e negativos, dependendo do comportamento da conexão ser excitatória ou inibitório, respectivamente. O aprendizado diz respeito às regras utilizadas para o ajuste dos pesos da rede e que informação é utilizada pela regra $[3,1]$.

Dentre os tipos de RNAs, destacam-se as redes diretas e as redes com retropropagação. As redes diretas, são aquelas em que os dados de entrada se propagam apenas da camada de entrada para a camada de saída, passando pelas intermediárias que possam existir, sendo conhecidas como feedforward. As redes recorrentes permitem que um neurônio receba em 
seus terminais de entrada a saída de um neurônio da mesma camada ou de uma camada posterior $[3,4,1]$.

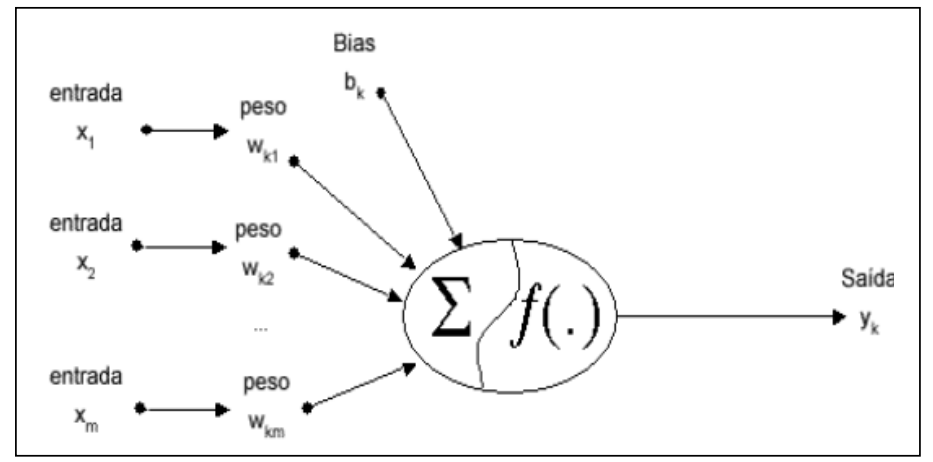

Figura 2: Neurônio Artificial

\section{Abordagem Proposta}

A base de dados utilizada foi obtida de uma empresa brasileira, internacionalmente reconhecida pelos padrões de qualidade do metal produzido. Foram coletados dados reais de: resistência, corrente, tensão, subida e descida do anodo e frequência de alimentação. Estas variáveis são capazes de representar, com um grau de aproximação satisfatório, o comportamento de um forno de redução de alumínio. Porém, alguns fenômenos inerentes ao processo não podem ser reproduzidos pelo modelo apenas com o status destas variáveis.

Para simular estes modelos foram utilizado um conjunto de 47604 amostras, dividido em treinamento $(28562-60 \%)$, validação $(9520-20 \%)$ e testes $(9520-20 \%)$, seguindo a metodologia Cross Validation.

Os parâmetros do RNMD e RNR foram os mesmos utilizados para a modelagem. Os parâmetros são: numero de épocas iguais a 60; objetivo a ser alcançado igual a 0.00001; algoritmo de treinamento Levenberg-marquardt utilizando-se as funções de ativação, em todos os casos, Sigmóide nas camadas escondidas e Linear na Camada de Saída.

Com os dados possíveis de serem coletados e mais relevantes e, foram realizadas simulações, variando as topologias dos dois tipos de redes neurais, buscando-se encontrar a melhor topologia para cada tipo de rede, comparando os melhores resultados.

\section{Análise de Resultados}

O software MATLAB R2012b [5] foi utilizado na realização dos experimentos. Esta ferramenta contém um toolbox de Redes Neurais (nnet), que possui implementações das redes neurais utilizadas neste trabalho, que também podem ser utilizadas em problemas de classificação, predição, controle e outros.

Devido às faixas de valores das variáveis utilizadas serem distintas, optou-se por normalizar os dados para o intervalo [0,1]. Em seguida, os dados foram organizados em 3 conjuntos: treinamento (utilizados para atualizar os pesos), validação (utilizados para evitar 
a super especialização da rede -overfitting) e teste (objetivo de examinar o grau de generalização da rede).

O treinamento, teste e validação da RNA foram realizados com os dados de entrada: subida e descida de anodo $\left(S_{t}\right.$ e $\left.D_{t}\right)$ respectivamente, intensidade da corrente $\left(I_{t}\right)$, frequência de alimentação $\left(\mathrm{C}_{\mathrm{t}}\right)$ e tensão instantânea do forno $\left(\mathrm{V}_{\mathrm{t}}\right)$. Sendo que os vetores de entrada, relacionadas a tensão e corrente instantânea, dão origem a dois outros vetores atrasados de 1 valor temporal $\left(\mathrm{V}_{\mathrm{t}-1}\right.$ e $\left.\mathrm{I}_{\mathrm{t}-1}\right)$. Este tipo de configuração permite que RNA relacione a proposta futura $(\mathrm{t}+1)$ com os valores atuais ( $\mathrm{t}$ ) e com estados passados ( $\mathrm{t}-1)$ conforme mostra na Figura 3.

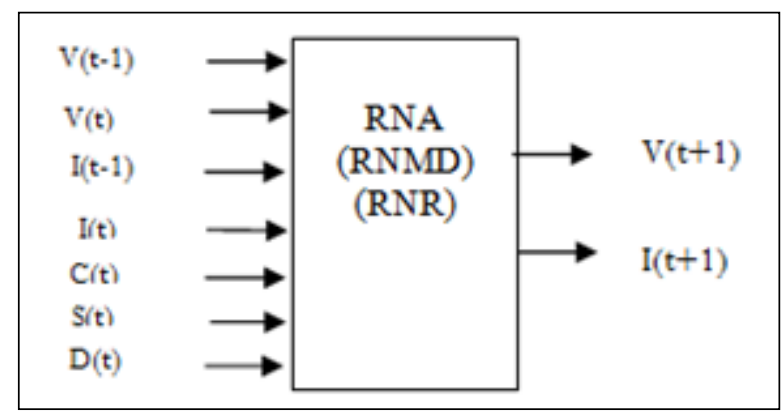

Figura 3: Estrutura Neural da Resistência Elétrica

Para topologia RNMD as simulações foram realizadas considerando as seguintes topologias:

- Uma camada escondida com variação da quantidade neurônios de 3 a 30 desta camada.

- Duas camadas escondidas com variação da quantidade neurônios de 3 a 15 e 2 a 20 respectivamente destas camadas.

- Três camadas escondidas com variação da quantidade neurônios de 3 a 15, 2 a 20 e 2 a 20 respectivamente destas camadas.

Para topologia RNR as simulações foram realizadas considerando as seguintes topologias:

- Uma camada escondida variando a quantidade de neurônios (3 a 15), utilizando como retroalimentação a saída da camada oculta e levando-se em consideração os atrasos definidos, ou melhor, acrescentando com os dados de entrada vetores atrasados de 1 valor temporal (tensão $V_{t-1}$ e corrente $I_{t-1}$ para o modelo ) e não definidos gerados pela própria rede.

As Tabelas 2 e 3 apresentam os melhores resultados encontrados para as topologias RNMD e RNR. Observa-se que a RNMD com 3 camadas obteve o menor erro de validação.

Tabela 2. Resultados da RNMD. 


\begin{tabular}{|c|c|c|c|}
\hline Quantidade de Neurônios & $\begin{array}{c}\text { Erro } \\
\text { Treinamento }\end{array}$ & $\begin{array}{c}\text { Erro } \\
\text { Validação }\end{array}$ & $\begin{array}{c}\text { Erro } \\
\text { Teste }\end{array}$ \\
\hline 1 Camada Oculta com 5 Neurônios & $1.7942 \mathrm{e}-05$ & $9.1168 \mathrm{e}-06$ & $6.8037 \mathrm{e}-06$ \\
\hline 2 Camadas Ocultas com 5 e 18 Neurônios & $1.7037 \mathrm{e}-05$ & $8.0248 \mathrm{e}-06$ & $1.1942 \mathrm{e}-05$ \\
\hline 3 Camadas Ocultas com 3,2 e 19 & $1.8451 \mathrm{e}-05$ & $4.7689 \mathrm{e}-06$ & $9.1408 \mathrm{e}-05$ \\
\hline $\begin{array}{c}\text { Neurônios } \\
\text { (19 }\end{array}$ & & & \\
\hline
\end{tabular}

Tabela 3.Resultados da RNR.

\begin{tabular}{|l|c|c|c|c|}
\hline \multicolumn{1}{|c|}{ Arquitetura } & $\begin{array}{c}\text { Quantidade } \\
\text { Neurônios na } \\
\text { camada Oculta 1 }\end{array}$ & $\begin{array}{c}\text { Erro } \\
\text { Treinamento }\end{array}$ & $\begin{array}{c}\text { Erro } \\
\text { Validação }\end{array}$ & $\begin{array}{c}\text { Erro } \\
\text { Teste }\end{array}$ \\
\hline $\begin{array}{l}\text { Com atraso } \\
\text { definido }\end{array}$ & 6 & $1.7113 \mathrm{e}-05$ & $8.7193 \mathrm{e}-06$ & $1.8548 \mathrm{e}-05$ \\
\hline $\begin{array}{l}\text { Sem atraso } \\
\text { definido }\end{array}$ & 14 & $1.9102 \mathrm{e}-05$ & $1.0880 \mathrm{e}-05$ & $2.2581 \mathrm{e}-06$ \\
\hline
\end{tabular}

A Figura 4 apresenta os valores reais e os resultados obtidos pela RNMD com 3 camadas para os vetores de tensão $\left(\mathrm{V}_{\mathrm{t}+1}\right)$ e corrente $\left(\mathrm{I}_{\mathrm{t}+1}\right)$. Devem ser levados em consideração alguns aspectos. O primeiro diz respeito à inclusão de uma parada do forno durante a coleta. Este evento pode ser encarado como uma forte perturbação e que mesmo assim o modelo reagiu adequadamente. Segundo, a rede recorrente foi a que obteve o menor erro de teste, portanto maior generalização.

De fato, a experiência prática diz que mais de duas camadas não resulta em melhora de desempenho e como é possível perceber a RNA conseguiu mapear satisfatoriamente os valores de tensão instantânea e intensidade da corrente.

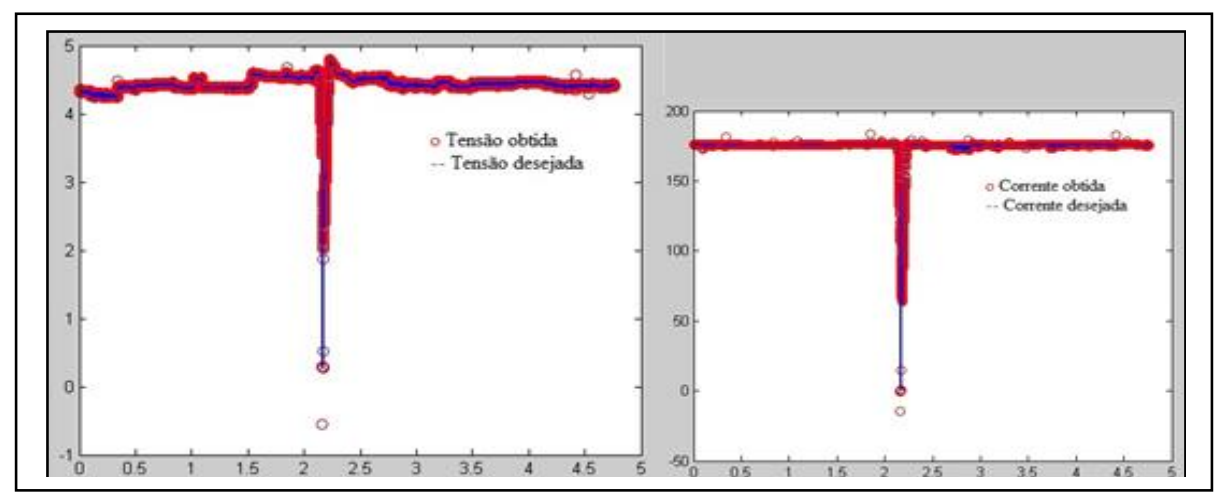

\section{Conclusão}

Figura 4 - Resultados obtidos 
Este trabalho teve como objetivo demonstrar à aplicabilidade de modelos neurais em problemas industriais, através da modelagem do comportamento a resistência elétrica de um forno de redução de alumínio primário.

Os resultados mostram que a melhor RNA para essa modelagem é a rede neural direta multicamada com várias camadas intermediárias.

A implantação do modelo neural no forno de redução apresenta uma nova contribuição com relação às propostas na busca da otimização operacional da unidade. Com o entendimento e o controle efetivo da resistência, será possível desenvolver um sistema que resultará em ganhos de produtividade e redução do custo operacional. Além disso, o mesmo modelo pode ser adaptado para a tarefa de predição de valores futuros de resistência do forno, dadas mudanças no volume de Alumina, por exemplo.

\section{Referências}

[1] A. P. Braga, A. C. P. L. F. Carvalho e T. B. Ludemir, Redes Neurais Artificiais Teoria e Aplicações, 2. ed. Rio de Janeiro: Ltc, 2007.

[2] M. V. M. Branco, Modelo Neural da Variação de Resistência Elétrica em um Forno de Redução de Alumínio para fins de Controle, Dissertação de Mestrado em Engenharia Elétrica - Universidade Federal do Pará, Alumínio Brasileiro S A, 2004.

[3] K . Faceli, A. C. Lorena, J. Gama e A. C. P. L. F. Carvalho, Inteligência Artificial Uma Abordagem de Aprendizado de Máquina. Rio de Janeiro: LTC, 2011.

[4] S. Haykin, Redes Neurais: Princípios e Prática, 2. ed.Porto Alegre: Bookman, 2001.

[5] MATLAB. Linguagem de computação Técnica e simulação. 2015. Disponível em: http://www.mathworks.com. Acesso em: 20 jul. 2015.

[6] F. J. S. Mcfadden, B. J. Welch, D. Whitfield and M. S. Kazacos, Control of Temperature in Aluminium Reduction Cells - Challenges in Measurements and Variability TMS Light Metals 2001 - Proceedings of the Technical Sessions, 130rd Technical TMS Annual Meeting, February11-15, New Orleans.

[7] S. Prasad, Studies on the Hall-Heroult Aluminium electro winning Process, Journal of Brazilian Chemistry Society, May/June 2000, vol. 11, no.3, 245-251.

[8] F. M. Soares e R. C. L Oliveira, Inferência de Temperatura de Fornos de Redução de Alumínio Primário através de Sensores Virtuais, IX Congresso Brasileiro de Redes Neurais, Ouro Preto-MG 25-28 de Outubro de 2009. 